\title{
A Neutron and X-ray Diffraction Study of the Structure of Nd Phosphate Glasses
}

\author{
Uwe Hoppe, Heike Ebendorff-Heidepriem ${ }^{\mathrm{a}}$, Jörg Neuefeind ${ }^{\mathrm{b}}$, and Daniel T. Bowron ${ }^{\mathrm{c}}$ \\ Universität Rostock, Fachbereich Physik, Universitätsplatz 3, D-18051 Rostock \\ ${ }^{a}$ Friedrich-Schiller-Universität Jena, Otto-Schott-Institut, Chemisch-Geowissenschaftliche \\ Fakultät, Fraunhoferstr. 6, D-07743 Jena \\ ${ }^{\mathrm{b}}$ Hamburger Synchrotronstrahlungslabor HASYLAB am Deutschen Elektronen-Synchrotron \\ DESY, Notkestr. 85, D-22607 Hamburg \\ ${ }^{c}$ ISIS Facility, Rutherford Appleton Laboratory, Chilton, Didcot OX11 0QX, UK \\ Reprint requests to Dr. U. H.; E-mail: hoppe@ @hysik1.uni-rostock.de
}

Z. Naturforsch. 56 a, 237-243 (2001); received January 8, 2001

\begin{abstract}
Diffraction experiments were performed on two $\left(\mathrm{Nd}_{2} \mathrm{O}_{3}\right)_{x}\left(\mathrm{P}_{2} \mathrm{O}_{5}\right)_{1-x}$ glasses for studying the environmental order of the $\mathrm{Nd}^{3+}$ cations. In case of the metaphosphate glass $(x=0.25)$ a combination of X-ray and neutron diffraction data was used to separate the $\mathrm{Nd}-\mathrm{O}$ and O-O first neighbor peaks. An Nd-O coordination number of $6.6 \pm 0.3$ and a mean Nd-O distance of $(0.239 \pm 0.001) \mathrm{nm}$ were determined. In the ultraphosphate glass studied $(x=0.20)$ these values increase to $6.9 \pm 0.3$ and $(0.240 \pm 0.001) \mathrm{nm}$ where the Nd-O coordination number is equal to the number of terminal oxygen atoms $\left(\mathrm{O}_{\mathrm{T}}\right)$ which are available for coordination of each $\mathrm{Nd}^{3+}$ cation. This indicates the formation of $\mathrm{NdO}_{n}$ polyhedra not sharing any $\mathrm{O}$ atom where also all $\mathrm{O}_{\mathrm{T}}$ 's are in $\mathrm{Nd}-\mathrm{O}_{\mathrm{T}}-\mathrm{P}$ positions. In the metaphosphate glass the $\mathrm{NdO}_{n}$ polyhedra have to share some $\mathrm{O}_{\mathrm{T}}$ sites.
\end{abstract}

Key words: Neutron Scattering; X-ray Scattering; Short-range Order; Phosphate Glasses.

\section{Introduction}

Various properties of the phosphate glasses make them advantageous for being host materials of lanthanide oxides $\mathrm{Ln}_{2} \mathrm{O}_{3}$ in applications for lasers or magneto-optical devices [1]. One of the networkmodifying cations for laser applications is the $\mathrm{Nd}^{3+}$ cation $[2,3]$ where, typically, $\mathrm{Nd}_{2} \mathrm{O}_{3}$ is a minor fraction among other modifier oxides. The environmental order and the distances between the $\mathrm{Nd}$ sites are an essential factor for the optical properties [2]. Small widths of a fluorescence line of $\mathrm{Eu}^{3+}$ sites in sodium phosphate glasses as host materials, if compared with those of other glass-forming systems, indicate a small variety of the environments of the $\mathrm{Eu}^{3+}$ sites [4]. This behavior may be due to the large flexibility of the surrounding oxygen sites. Also binary Ln phosphate glasses can be prepared which have large $\mathrm{Ln}_{2} \mathrm{O}_{3}$ fractions of up to 25 mole\%. Some unusual magnetic properties were detected for several of these phosphate materials [5].
The diffraction study here presented is focussed on binary $\mathrm{Nd}$ phosphate glasses where two samples of different $\mathrm{Nd}_{2} \mathrm{O}_{3}$ fractions were used. The most stable glasses are obtained in a range close to the metaphosphate composition where long chains and ring structures of corner-linked $\mathrm{PO}_{4}$ units exist. The structural units and their connectivities are well investigated by vibrational spectroscopy or by ${ }^{31} \mathrm{P}$ nuclear magnetic resonance (NMR) spectroscopy (cf. [6]). For studying the oxygen coordination of the $\mathrm{Ln}^{3+}$ cations, neutron and X-ray diffraction (ND and XRD) experiments or extended X-ray absorption fine structure (EXAFS) spectroscopy are applied [7 - 15]. A decrease of the Ln-O first-neighbor distances along with the increase of the electron number of the $\mathrm{Ln}$ species was shown by EXAFS for the glasses $\left(\mathrm{Ln}_{2} \mathrm{O}_{3}\right)_{x}\left(\mathrm{P}_{2} \mathrm{O}_{5}\right)_{1-x}$ with $x$ varying in a range from 0.19 to $0.26[8,12,15]$. Though some of the Ln-O coordination numbers, $N_{\text {LnO }}$, obtained vary from 5 to 8 , a decrease from 6.5 for $N_{\mathrm{LaO}}$ to 6.0 for $N_{\mathrm{ErO}}$ is suggested [12], which is also concluded from the behavior of the $\mathrm{Ln}-\mathrm{O}$ 
distances. A number $N_{\mathrm{LaO}}$ of seven was found in a combination of XRD and ND data of a $\mathrm{LaP}_{3} \mathrm{O}_{9}$ glass [10].

A further question concerns the effects of $N_{\mathrm{LnO}}$ when the composition $x$ is varied. For two different Ce phosphate glasses an $N_{\mathrm{CeO}}$ of six and no essential change were detected, as reported in [15]. These findings differ from the behavior of the $N_{\mathrm{LnO}}$ 's which is known for the related crystal structures. The number $N_{\mathrm{NdO}}$ is eight in $\mathrm{NdP}_{5} \mathrm{O}_{14}$, and it changes to six in $\mathrm{NdP}_{3} \mathrm{O}_{6}$ crystals [16]. But two additional $\mathrm{O}$ sites exist in $\mathrm{NdP}_{3} \mathrm{O}_{9}$ at $\mathrm{Nd}-\mathrm{O}$ distances larger by $0.03 \mathrm{~nm}$, which are not found in $\mathrm{LnP}_{3} \mathrm{O}_{9}$ crystals of the smaller $\mathrm{Ln}^{3+}$ cations such as in $\mathrm{ErP}_{3} \mathrm{O}_{9}$ [17]. The $N_{\mathrm{LnO}}$ 's of eight and six in $\mathrm{LnP}_{5} \mathrm{O}_{14}$ and $\mathrm{LnP}_{3} \mathrm{O}_{9}$ crystals are equal to the numbers $M_{\text {TO }}$ of terminal oxygen atoms $\left(\mathrm{O}_{\mathrm{T}}\right)$ which are available to coordinate each of the $\mathrm{Ln}^{3+}$ cations. Consequently, the $\mathrm{O}_{\mathrm{T}}$ 's occupy positions in $\mathrm{P}^{-} \mathrm{O}_{\mathrm{T}}-\mathrm{Ln}$ bridges and the $\mathrm{LnO}_{n}$ polyhedra do not share any of their $\mathrm{O}_{\mathrm{T}}$ atoms. Thus, the $\mathrm{Ln}$ sites are separated by $\mathrm{PO}_{4}$ units. First, such specifics were detected for phosphate glasses of the bivalent metal oxides $\mathrm{MeO}$. Most of the anomalies of their glass properties could be attributed to these effects [18]. The changes of the $N_{\mathrm{ZnO}}$ and $N_{\mathrm{MgO}}$ numbers which were detected in the ultraphosphate range [19-21] are due to a stabilization of those $\mathrm{MeO}_{n}$ polyhedra which do not share in the use of the $\mathrm{O}_{\mathrm{T}}$ 's. In this process, the doubly-bonded $\mathrm{O}_{\mathrm{T}}$ 's of the threefold-linked $\mathrm{PO}_{4}$ units tend to coordinate an Me site too [18].

A first case of a change of the Me-O coordination number of a threevalent Me site was found by ${ }^{27} \mathrm{Al} \mathrm{NMR}$ in the $\left(\mathrm{Al}_{2} \mathrm{O}_{3}\right)_{x}\left(\mathrm{P}_{2} \mathrm{O}_{5}\right)_{1-x}$ glasses with $x$ of about 0.33 [22]. The decrease of $N_{\text {AlO }}$ from 5.3 to 4.8 when $\mathrm{Al}_{2} \mathrm{O}_{3}$ is added behaves as $M_{\text {TO }}$. Similar changes for the $\mathrm{Ln}-\mathrm{O}$ coordination numbers in $\left(\mathrm{Ln}_{2} \mathrm{O}_{3}\right)_{x}\left(\mathrm{P}_{2} \mathrm{O}_{5}\right)_{1-x}$ glasses are expected in a compositional range between $x=0.16$ and 0.25 according to $N_{\mathrm{LnO}}$ numbers between eight and six. The number $M_{\text {TO }}$ is calculated with $M_{\text {TO }}=(1+2 x) / x$ [22]. The $\mathrm{Nd}-\mathrm{O}$ coordination numbers of $\mathrm{Nd}$ phosphate glasses of two different compositions will be determined by the diffraction studies presented here. Since the Nd-O first-neighbor distance superposes with the lengths of the $\mathrm{O}-\mathrm{O}$ edges of the $\mathrm{PO}_{4}$ tetrahedra, a combination of ND and XRD data is advantageous to separate the two contributions. The XRD experiment is more important for a determination of $N_{\mathrm{NdO}}$ due to the large $\mathrm{X}$-ray scattering power of $\mathrm{Nd}$ atoms if compared with those of the other constituents.

\section{Experimental}

\subsection{Sample Preparation}

The raw materials in the preparation of the $\mathrm{Nd}$ phosphate glasses were $\mathrm{Nd}_{2} \mathrm{O}_{3}$ and $\mathrm{H}_{3} \mathrm{PO}_{4}$, where ratios of $1: 10$ and 1:6 were used in the 'as batch' compositions. The mixtures were melted in silica crucibles at temperatures of 1400 to $1450{ }^{\circ} \mathrm{C}$. According to the analysis of the $\mathrm{P}$ fraction and to a comparison of the IR spectra, the compositions of the final $\left(\mathrm{Nd}_{2} \mathrm{O}_{3}\right)_{x}\left(\mathrm{P}_{2} \mathrm{O}_{5}\right)_{1-x}$ glasses were estimated to $x \cong 0.20$ and 0.25 . The samples which are slightly different in their red color are labelled NdP4 and NdP3 according to the ratios $n(\mathrm{Nd}) / n(\mathrm{P})$. Since the melting temperatures are high, a significant amount of $\mathrm{SiO}_{2}$ or $\mathrm{Al}_{2} \mathrm{O}_{3}$ of crucible material can have entered the glass sample such as considered in [13,14]. Good information about the real glass compositions is needed for the analysis of the diffraction data. The use of vibrational spectroscopy for our samples gives a sufficient measure to obtain the degree of network depolymerization. Part of the $\mathrm{P}_{2} \mathrm{O}_{5}$ content of the NdP4 sample was lost due to evaporation. Also some effort was made to minimize the water contamination [23]. The use of sealed ampoules is recommended to avoid moisture attack and the loss of $\mathrm{P}_{2} \mathrm{O}_{5}$ for melting ultraphosphate samples of even smaller $\mathrm{Nd}_{2} \mathrm{O}_{3}$ fractions [24]. The mass densities were measured by the Archimedes principle using $\mathrm{CCl}_{4}$. Values of 3.14 and $3.31 \mathrm{~g} / \mathrm{cm}^{3}$ were obtained for the NdP4 and NdP3 samples, which correspond to number densities of atoms of 69.0 and $68.0 \mathrm{~nm}^{-3}$. Since only a very small amount of the sample NdP4 was available, an ND experiment of NdP4 was not possible.

\subsection{Diffraction Experiments}

The XRD experiments were performed on the BW5 wiggler beamline at the DORIS III synchrotron (Hamburg/Germany), where an energy of $130 \mathrm{keV}(\lambda=$ $0.00954 \mathrm{~nm}$ ) of the incident photons was used. Powdered sample material was loaded into silica capillaries of $2.0 \mathrm{~mm}$ diameter with a wall thickness of $0.01 \mathrm{~mm}$. During the measurements the specimens were positioned in a vacuum vessel to suppress air scattering. Since the scattering angles are small, the transmission factors are assumed to be independent of the angle. The angular increment in the step-scan mode was $0.05^{\circ}$. In the $2 \theta$-range from $0.35^{\circ}$ to $9^{\circ}$ 
an absorber was set in the diffracted beam to avoid counting rates higher than $10^{5} \mathrm{~s}^{-1}$. The other scans range from $8^{\circ}$ to $25^{\circ}$. Details of such experiments and the corrections are described in [25]. The electronic energy window of the solid-state Ge-detector was chosen to pass the elastic line and the full Compton profile but no fluorescence scattering. The deadtime corrections were made with $\tau=2.4 \mu \mathrm{s}$. A fraction of 0.91 of the incident photons is polarized horizontally. Both numbers allow to merge the data of the scans obtained for both angular ranges and with different synchrotron currents. Corrections are made for background, container scattering, and absorption. The scattering intensities are normalized to the structure-independent scattering functions which have been calculated by polynomial fits of the tabulated atomic parameters of the elastic and the Compton scattering data [26]. Finally, the Compton fractions are subtracted and Faber-Ziman structure factors, $S_{\mathrm{X}}(Q)$, are calculated [27].

The ND experiments of the NdP3 glass were performed on the time-of-flight instrument SANDALS of the pulsed neutron source ISIS at the Rutherford Appleton Laboratory. The powdered sample was loaded into a thin-walled vanadium cylinder of $5 \mathrm{~mm}$ diameter with a wall thickness of $0.025 \mathrm{~mm}$. The absorption and multiple scattering corrections are made by the ATLAS program suite [28]. The self scattering contributions are calculated according to the compositions of the samples where inelasticity effects are small due to the small scattering angles of SANDALS. The scattered intensities recorded in the various detector groups and normalized to separate self terms are merged to the differential scattering cross-section. Large resonance terms of the epithermal neutrons with the Nd nucleous limit the momentum transfer, $Q_{\max }$, to about $250 \mathrm{~nm}^{-1}$ with $Q=4 \pi / \lambda \sin \theta$. The incoherent scattering is subtracted and the total neutron structure factor, $S_{\mathrm{N}}(Q)$, is calculated [27].

\section{Results}

The structure factors of the two samples measured are shown in Figure 1. Due to the use of high-energy photons $(130 \mathrm{keV})$ the $S_{\mathrm{X}}(Q)$ functions are available up to $290 \mathrm{~nm}^{-1}$. The data of both samples are similar to each other except of the shoulder at $20 \mathrm{~nm}^{-1}$. The low- $Q$ feature, another shoulder at $11 \mathrm{~nm}^{-1}$, is already known for the $S_{\mathrm{X}}(Q)$ data of a $\mathrm{LaP}_{3} \mathrm{O}_{9}$ glass [10]. The neutron $S_{\mathrm{N}}(Q)$ function of the $\mathrm{NdP}_{3} \mathrm{O}_{9}$

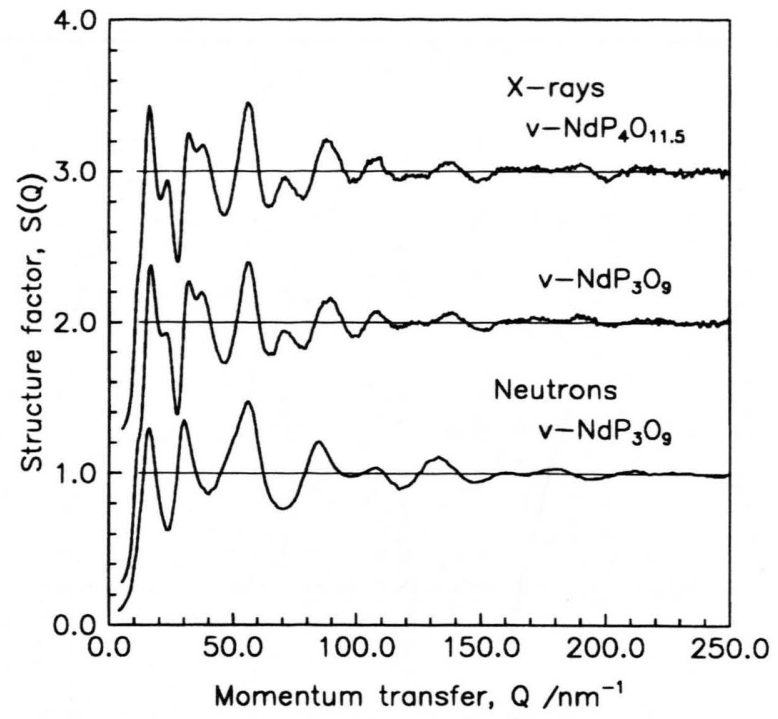

Fig. 1. Structure factors, $S(Q)$, of the two glasses studied obtained by $\mathrm{XRD}$ and for the $\mathrm{NdP}_{3} \mathrm{O}_{9}$ glass additionally obtained by ND experiments. The upper functions are shifted for clarity.

glass is very similar to that of the $\mathrm{Nd}$ phosphate glass of $x=0.187$ measured by Cole et al. [13], and also to that of the $\mathrm{LaP}_{3} \mathrm{O}_{9}$ glass [10]. The ND data [10,13] obtained on the LAD instrument* reach a $Q_{\max }$ of $500 \mathrm{~nm}^{-1}$. The smaller range of scattering angles available on the SANDALS instrument requires the use of neutrons of higher energies. Thus, the effects of the Nd resonances are obtained at smaller $Q$ which limits the $Q$-range of our data. Note that XRD experiments possess much weight in the determination of the $N_{\mathrm{NdO}}$ 's. The weighting factors of the partial $S_{\mathrm{NdO}}(Q)$ and $S_{\mathrm{OO}}(Q)$ functions in the $S_{\mathrm{X}}(Q)$ data of the NdP3 sample are 0.276 and 0.165 while in the $S_{\mathrm{N}}(Q)$ data the weighting factors are 0.142 and 0.481 , respectively.

The correlation functions, $T(r)$, are obtained by Fourier transformation (FT) with

$$
\begin{array}{r}
T_{k}(r)=4 \pi r \rho_{0}+\frac{2}{\pi} \int_{0}^{Q_{\max }} Q\left[S_{k}(Q)-1\right] \\
\cdot M(Q) \sin (Q r) \mathrm{d} Q,
\end{array}
$$

where $\rho_{0}$ is the number density of atoms. $M(Q)$ is a damping function, that according to Lorch [29] with $M(Q)=\sin \left(\pi Q / Q_{\max }\right) /\left(\pi Q / Q_{\max }\right)$ being applied.

*The LAD instrument at ISIS is dismantled and replaced by the more powerful instrument GEM. 


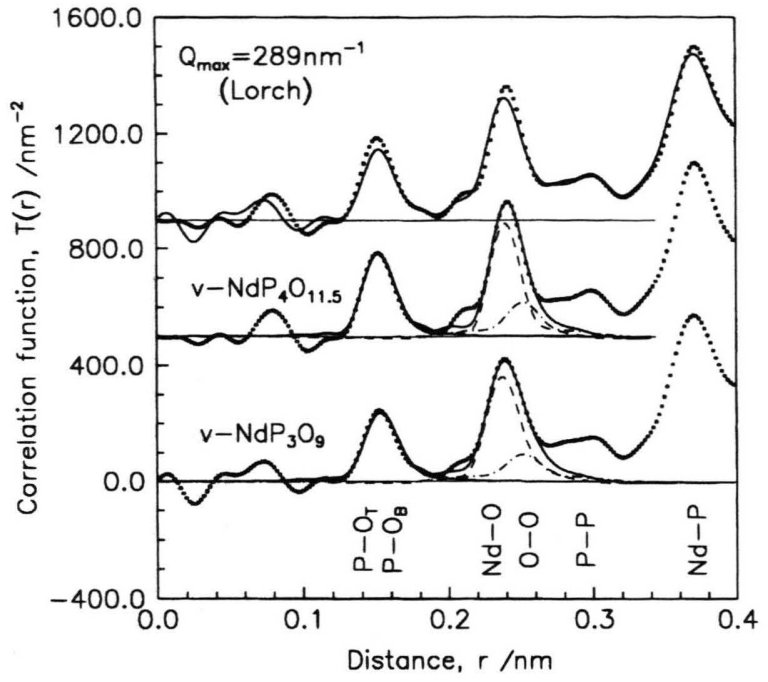

Fig. 2. On top, the correlation functions, $T_{\mathrm{X}}(r)$, of the glasses NdP3 (solid line) and NdP4 (dotted line) are compared in the range of the first three distance peaks. Below, the experimental $T_{\mathrm{X}}(r)$ data of the glasses NdP4 and NdP3 (dotted lines) are compared with the fitted model functions (solid lines). Additionally, the partial model functions are shown as peaks already weighted according to concentration and scattering power and broadened due to the effects of damping and $Q_{\max }$ with the contributions P-O (solid lines), $\mathrm{Nd}-\mathrm{O}$ (dashed lines), and O-O (dash-dotted lines). The P-O model peak is almost identical with the first $\mathrm{P}-\mathrm{O}$ peak (cf. Fig. 3). The upper functions are shifted for clarity.

The parameter $k$ is either $\mathrm{X}$ or $\mathrm{N}$ for the XRD and ND data. The $T(r)$ functions are shown in Figs. 2, 3, where the $Q_{\max }$ 's used are indicated in the plots. The $T_{\mathrm{X}}(r)$ functions are compared in Figure 2. All three peaks visible in the NdP4 data (dots) are higher than those in the NdP3 data (line). Since $N_{\mathrm{PO}}=4$ is not changed and the $\mathrm{P}$ fraction in NdP4 is larger than in NdP3, the $\mathrm{P}-\mathrm{O}$ peak must be higher for the NdP4 sample. On the other hand, since the $\mathrm{Nd}$ fraction is smaller in $\mathrm{NdP} 4$, the Nd-O and Nd-P peaks are expected to be smaller due to weighting factors of 0.246 and 0.160 smaller than 0.276 and 0.172 for NdP3. But the decrease is overcompensated by an increase of $N_{\mathrm{NdO}}$ and $N_{\mathrm{NdP}}$, which explains the increase of the $\mathrm{Nd}-\mathrm{O}$ and $\mathrm{Nd}-\mathrm{P}$ peaks.

The $N_{\mathrm{NdO}}$ 's are determined by Gaussian fitting. The effects of the damping function and the truncation at $Q_{\max }$ in the FT procedures are taken into account by a method described in [30]. Thus, also $Q$-dependent weighting factors are applied in case of the X-ray data [30]. For fitting the $T(r)$ data the Marquardt algorithm [31] is used, where coordination numbers, mean

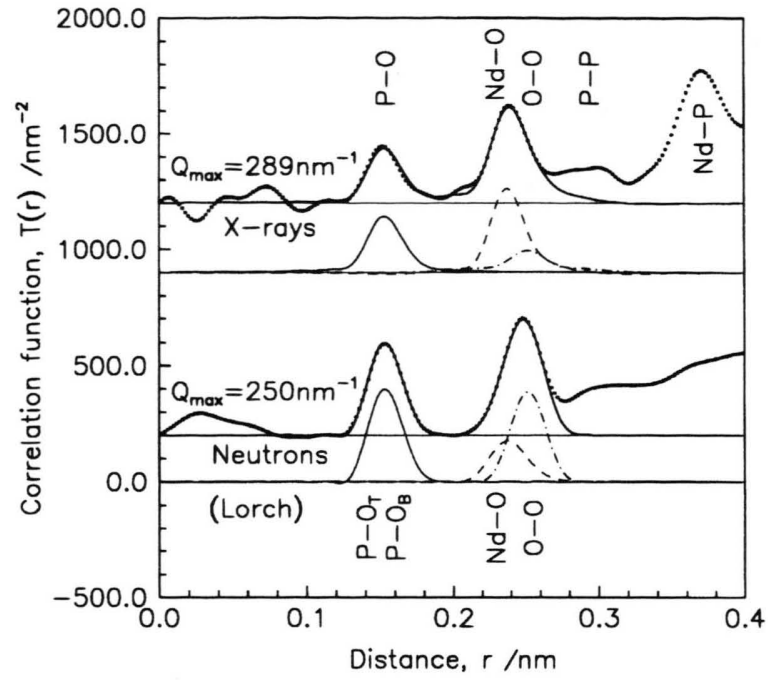

Fig. 3. Comparison of the experimental $T_{\mathrm{X}}(r)$ and $T_{\mathrm{N}}(r)$ data (dotted lines) of the NdP3 glass with the model functions (solid lines). Separately, the partial model functions are shown as peaks already weighted according to concentration and scattering power and broadened due to the effects of damping and $Q_{\max }$ with the contributions P-O (solid lines), Nd-O (dashed lines), and O-O (dash-dotted lines). The upper functions are shifted for clarity.

distances and full widths at half maximum (fwhm) are the parameters of the model Gaussian functions. Two Gaussian functions are used for fitting the $\mathrm{P}-\mathrm{O}$ peak with the $\mathrm{P}-\mathrm{O}_{\mathrm{T}}$ and $\mathrm{P}-\mathrm{O}_{\mathrm{B}}$ contributions $\left(\mathrm{O}_{\mathrm{B}}\right.$-bridging oxygen atom). A split P-O peak was found for other phosphate glasses by ND experiments of high resolving power $\left(Q_{\max } \cong 500 \mathrm{~nm}^{-1}\right)$ [32]. The ratios of the fractions of the $\mathrm{P}-\mathrm{O}$ bonds are fixed in the fits according to the degree of network depolymerization, which is determined by the compositions. The difference of the mean $\mathrm{P}-\mathrm{O}_{\mathrm{T}}$ and $\mathrm{P}-\mathrm{O}_{\mathrm{B}}$ bond lengths is fixed to $0.011 \mathrm{~nm}$. A possible asymmetry of the $\mathrm{Nd}-\mathrm{O}$ peak is approximated using two Gaussian functions, which does not imply the existence of two Nd-O distances. Some of the six parameters have to be fixed (Table 1). No information of a second $\mathrm{Nd}-\mathrm{O}$ peak at $0.27 \mathrm{~nm}$, such as it exists in the $\mathrm{NdP}_{3} \mathrm{O}_{9}$ crystal [16], can be given. Due to peak overlapping in the concerning distance range such $\mathrm{Nd}-\mathrm{O}$ distances cannot be extracted from total $T(r)$ data. The fifth Gaussian function approximates the O-O peak. All resulting peak parameters are given in Table 1. Only the combined fit of $\mathrm{ND}$ and XRD data of the NdP3 glass allows to extract the O-O contributions (Fig. 3). The O-O coordination number depends on the degree of network depoly- 
Table 1. Parameters of the Gaussian functions which result from the fit of the first-neighbor peaks. The distances and full widths at half maximum (fwhm) are given in $\mathrm{nm}$. The parameters marked by asterisks were fixed during the fit. Their choice is explained in the text. The errors given in parentheses are estimated according to the reproducibility of the parameters after the data corrections and the Gaussian fitting.

\begin{tabular}{|c|c|c|c|c|c|c|}
\hline $\begin{array}{l}\text { Sam- } \\
\text { ple }\end{array}$ & $\begin{array}{l}\text { Atom } \\
\text { pair }\end{array}$ & $\begin{array}{l}\text { Coordi- } \\
\text { nation } \\
\text { number }\end{array}$ & Distance & fwhm & $\begin{array}{l}\text { Total } \\
\text { coordin. } \\
\text { number }\end{array}$ & $\begin{array}{l}\text { Mean } \\
\text { distance }\end{array}$ \\
\hline NdP3 & $\begin{array}{l}\mathrm{P}-\mathrm{O}_{\mathrm{T}} \\
\mathrm{P}-\mathrm{O}_{\mathrm{B}} \\
\mathrm{Nd}-\mathrm{O} \\
\mathrm{O}-\mathrm{O}\end{array}$ & $\begin{array}{l}2.10(10) \\
2.10(10) \\
4.7(4) \\
1.9(3) \\
4.07(20)\end{array}$ & $\begin{array}{l}0.1490(5) \\
0.1600(5) \\
0.2360(15) \\
0.2480^{*} \\
0.2515(15)\end{array}$ & $\begin{array}{l}0.009(3) \\
0.016(4) \\
0.019(3) \\
0.030 * \\
0.020(3)\end{array}$ & $\begin{array}{l}4.2(2) \\
6.6(3)\end{array}$ & $0.1545(10)$ \\
\hline NdP4 & $\begin{array}{l}\mathrm{P}-\mathrm{O}_{\mathrm{T}} \\
\mathrm{P}-\mathrm{O}_{\mathrm{B}} \\
\mathrm{Nd}-\mathrm{O} \\
\mathrm{O}-\mathrm{O}\end{array}$ & $\begin{array}{l}1.73(10) \\
2.22(10) \\
5.5(4) \\
1.4(3) \\
4.17^{*}\end{array}$ & $\begin{array}{l}0.1470(5) \\
0.1580(5) \\
0.2385(15) \\
0.2480^{*} \\
0.2515^{*}\end{array}$ & $\begin{array}{l}0.004(3) \\
0.015(4) \\
0.017(3) \\
0.030^{*} \\
0.019(3)\end{array}$ & $\begin{array}{l}3.95(20) \\
6.9(3)\end{array}$ & $0.1532(10)$ \\
\hline
\end{tabular}

merization with $N_{\mathrm{OO}}=24 /(5+y)$ [19] where, $y$ is the ratio $n\left(\mathrm{Ln}_{2 / 3} \mathrm{O}\right) / n\left(\mathrm{P}_{2} \mathrm{O}_{5}\right)$ with $y=3 x /(1-x)$. $N_{\text {OO }}$ is expected to be four for the NdP3 glass with $y=1$ or $x=0.25$. Actually, $N_{\mathrm{OO}}=4.07$ is obtained from the fit, which is a good agreement. For the NdP4 glass an $N_{\text {OO }}$ of 4.17 is calculated. Together with the $\mathrm{O}-\mathrm{O}$ distance $\left(r_{\mathrm{OO}}=0.2515 \mathrm{~nm}\right)$ this value is fixed in the fit of the $T_{\mathrm{X}}(r)$ data of the NdP4 glass. The model functions which correspond to the $\mathrm{P}-\mathrm{O}, \mathrm{Nd}-\mathrm{O}$, and O-O distances are shown in Figs. 2 and 3, as well. Figure 2 illustrates that $\mathrm{Nd}-\mathrm{O}$ coordination numbers cannot be obtained from the $T_{\mathrm{X}}(r)$ data without assumptions about the $\mathrm{O}-\mathrm{O}$ peak. Figure 3 shows the combination of the $T_{\mathrm{X}}(r)$ and $T_{\mathrm{N}}(r)$ data. The $T_{\mathrm{N}}(r)$ data are excellently fitted while the $T_{\mathrm{X}}(r)$ data show unreasonable features at $0.21 \mathrm{~nm}$ and below $0.1 \mathrm{~nm}$. The increase of $N_{\mathrm{NdO}}$ from $6.6(\mathrm{NdP} 3)$ to $6.9(\mathrm{NdP} 4)$ is accompanied by an increase of the mean $r_{\mathrm{NdO}}$ by only $0.001 \mathrm{~nm}$, whereby the asymmetry of the peak is reduced. The changes lie in the uncertainty limit of XRD experiments. However, due to the use of the same experimental conditions for both samples we would interprete the increase of $N_{\mathrm{NdO}}$ in the NdP4 glass as a real change. Since every $\mathrm{O}$ atom in an $\mathrm{NdO}_{n}$

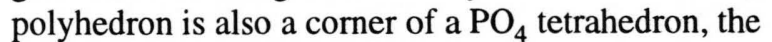
increase of $N_{\mathrm{NdO}}$ is accompanied by an increase of $N_{\mathrm{NdP}}$. The linkage of an $\mathrm{Nd}$ site with a $\mathrm{PO}_{4}$ tetrahedron by edges is an unfavourable situation [18]. The increase of the Nd-P peak for the NdP4 sample, which is visible in Fig. 2, is explained by this increase of $N_{\mathrm{NdP}}$ because the weighting factor even decreases from 0.172 to 0.160 . An exact determination of the Nd-P coordination number from the total $T(r)$ data is not possible.

\section{Discussion}

Commonly, the oxygen coordination numbers of the network-modifying cations in oxide glasses are not expected to vary much. Changes in the number of oxygen atoms supplied for their coordination may cause such effects. The number of $\mathrm{O}_{\mathrm{T}}$ atoms per modifier cation, $M_{\mathrm{TO}}$, is large in phosphate glasses. In a first line, the $\mathrm{O}_{\mathrm{B}}$ 's do not participate in this process. The number $M_{\text {TO }}$ may even equal the oxygen coordination number of a modifier cation [18]. This situation suggests that all $\mathrm{O}_{\mathrm{T}}$ 's could have exactly one modifier neighbor, and no modifier cation, here the $\mathrm{Nd}^{3+}$ cations, would have to share an oxygen neighbor with a further $\mathrm{Nd}^{3+}$ site. For threefold-charged cations $M_{\text {TO }}$ equals $(1+2 x) / x$ [22]. Thus, the NdP4 and NdP3 glasses studied with $x=0.20$ and 0.25 can form the described glass structures with $\mathrm{Nd}-\mathrm{O}$ coordination numbers of seven and six. The number $N_{\mathrm{NdO}}$ of $6.9 \pm 0.3$ of the NdP4 glass (Table 1) is equal to $M_{\mathrm{TO}}=7$ which allows the formation of $\mathrm{NdO}_{n}$ polyhedra not sharing any $\mathrm{O}_{\mathrm{T}}$ sites. All $\mathrm{O}_{\mathrm{T}}$ 's can have one $\mathrm{Nd}$ neighbor. The individual numbers $n$ are presumably not only seven, but a distribution with numbers six, seven and eight is formed. Diffraction experiments yield mean coordination numbers. For the sample NdP3 the $N_{\mathrm{NdO}}$ observed, $6.6 \pm 0.3$, is larger than six. The building principle of separate $\mathrm{NdO}_{n}$ polyhedra is not realised, though the decrease of $M_{\text {TO }}$ induces a small decrease of $N_{\mathrm{NdO}}$. The situation for the $\mathrm{NdP}_{3} \mathrm{O}_{9}$ crystal [16] is similar, where the two $\mathrm{O}$ sites at $0.270 \mathrm{~nm}$ in addition to the six at $0.236 \mathrm{~nm}$ indicate that a structure with only $\mathrm{NdO}_{6}$ octahedra is not stable and the $\mathrm{NdO}_{n}$ polyhedra share in some $\mathrm{O}_{\mathrm{T}}$ neighbors. Consequently, some smaller Nd-Nd distances should occur which do not exist in the NdP4 glass and which may have effects on the optical properties. Reverse Monte Carlo simulations of the structure of a $\mathrm{LaP}_{3} \mathrm{O}_{9}$ glass [10] revealed a few short La-La distances of $0.45 \mathrm{~nm}$ which belong to $\mathrm{LaO}_{n}$ polyhedra sharing in an $\mathrm{O}_{\mathrm{T}}$ while a larger number of La-La distances of about $0.65 \mathrm{~nm}$ is due to a separation by a common $\mathrm{PO}_{4}$ neighbor. The smaller of the lanthanide cations can form structures with coordination numbers of six also in their metaphosphate 
glasses $[12,17]$, thus with separate $\mathrm{LnO}_{6}$ octahedra. In the ultraphosphate range the formation of separate $\mathrm{LnO}_{n}$ octahedra is possible for all $\mathrm{Ln}^{3+}$ cations such as found for $\mathrm{Nd}^{3+}$ in the $\mathrm{NdP} 4$ sample with an $N_{\mathrm{NdO}}$ of about seven.

When the change of $N_{\mathrm{NdO}}$ in accordance with $M_{\mathrm{TO}}$ is discussed, the question about the reasons for this process arises. In a first line, the phenomenon should be attributable to principles of charge compensation. Two tendencies may be important [18]: all $\mathrm{O}_{\mathrm{T}}$ sites, also those of the threefold-connected $\mathrm{PO}_{4}$ branching units, aspire to coordinate a modifier cation. Such neighbors would weaken the $\pi$-character of the $\mathrm{P}-\mathrm{O}_{\mathrm{T}}$ bond, this effect being known from Raman spectra [6]. Secondly, $\mathrm{LnO}_{n}$ polyhedra whose vertices are all connected with corners of $\mathrm{PO}_{4}$ tetrahedra and not with vertices of other $\mathrm{LnO}_{n}$ polyhedra can form more spherical clouds of countercharge which is favoured against any sharing of $\mathrm{O}_{\mathrm{T}}$ sites with other Ln's. Therefore, the $\mathrm{Ln}-\mathrm{O}$ coordination number is changed to equal $M_{\mathrm{TO}}$, the number of which depends on the modifier content (see above). This phenomenon appears in a definite compositional range according to the possible coordination states of the modifier cation. The two samples studied show the transition from a glass with separate $\mathrm{NdO}_{n}$ polyhedra (NdP4) to a glass with some sharing of $\mathrm{O}_{\mathrm{T}}$ sites between the $\mathrm{NdO}_{n}$ polyhedra (NdP3). The formation of more symmetric $\mathrm{NdO}_{n}$ polyhedra in phosphate glasses is also made easy by the high flexibility of the $\mathrm{O}_{\mathrm{T}}$ sites. The $\mathrm{PO}_{4}$ tetrahedra in the glasses studied are connected by only two or

[1] M. J. Weber, in: J. Zarzycki (Ed.), Materials Science and Technology, A Comprehensive Treatment, vol. 9, VCH, Weinheim 1991, p. 654.

[2] H. Ebendorff-Heidepriem, W. Seeber, and D. Ehrt, J. Non-Cryst. Solids 183, 191 (1995).

[3] J. H. Campbell and T. I. Suratwala, J. Non-Cryst. Solids 263\&264, 318 (2000).

[4] K. Hirao, S. Todoroki, and N. Soga, J. Non-Cryst. Solids 175, 263 (1994).

[5] G. Carini, G. D’Angelo, G. Tripodo, A. Bartolotta, A. Fontana, F. Rossi, and G. A. Saunders, Philos. Mag. B 77, 449 (1998).

[6] R. K. Brow, J. Non-Cryst. Solids 263\&264, 1 (2000) and references therein.

[7] D. T. Bowron, R. J. Newport, B. D. Rainford, G. A. Saunders, and H. B. Senin, Phys. Rev. B 51, 5739 (1995). three corners, in NdP3 only by two corners. The $\mathrm{PO}_{4}$ tetrahedra can be orientated as needed.

\section{Conclusions}

Diffraction experiments were performed on two $\left(\mathrm{Nd}_{2} \mathrm{O}_{3}\right)_{x}\left(\mathrm{P}_{2} \mathrm{O}_{5}\right)_{1-x}$ glasses with $x=0.20$ and 0.25 . In case of the metaphosphate glass $(0.25)$ the combination of X-ray and neutron diffraction data allowed to separate the $\mathrm{Nd}-\mathrm{O}$ and $\mathrm{O}-\mathrm{O}$ first neighbor peaks and to determine an Nd-O coordination number of $6.6 \pm 0.3$ and a mean Nd-O distance of $0.239 \pm 0.001 \mathrm{~nm}$. Similar numbers, somewhat larger than six, were also published for the metaphosphate glasses of other lanthanide cations of similar dimension. In the ultraphosphate glass studied $(x=0.2)$ somewhat larger $\mathrm{Nd}-\mathrm{O}$ coordination number of $6.9 \pm 0.3$ is detected, which is equal to the number $M_{\text {TO }}$ of terminal oxygen atoms $\left(\mathrm{O}_{\mathrm{T}}\right)$ available for coordination of each modifier cation. This situation allows the formation of $\mathrm{NdO}_{n}$ polyhedra not sharing any $\mathrm{O}$ atoms where also all $\mathrm{O}_{\mathrm{T}}$ 's are in $\mathrm{Nd}^{-} \mathrm{O}_{\mathrm{T}}-\mathrm{P}$ positions. The study of compositional changes of $N_{\mathrm{NdO}}$ requires samples whose compositions are well known. Their preparation is difficult especially in the ultraphosphate range where moisture, crucible material and phosphate evaporation can affect the melt compositions.

\section{Acknowledgement}

Financial support of the BMBF (Grant 03KR5ROK-9) is gratefully acknowledged.

[8] D. T. Bowron, G. A. Saunders, R. J. Newport, B. D. Rainford, and H. B. Senin, Phys. Rev. B 53, 5268 (1996).

[9] D. T. Bowron, G. Bushnell-Wye, R. J. Newport, B. D. Rainford, and G. A. Saunders, J. Phys.: Condens. Matter 8, 3337 (1996).

[10] U. Hoppe, R. Kranold, D. Stachel, A. Barz, and A. C. Hannon, J. Non-Cryst. Solids 232-234, 44 (1998).

[11] R. Anderson, T. Brennan, G. Mountjoy, R. J. Newport, and G. A. Saunders, J. Non-Cryst. Solids 232-234, 286 (1998).

[12] R. Anderson, T. Brennan, J. M. Cole, G. Mountjoy, D. M. Pickup, R. J. Newport, and G. A. Saunders, J. Mater. Res. 14, 4706 (1999).

[13] J. M. Cole, E. R. H. van Eck, G. Mountjoy, R. J. Newport, T. Brennan, and G. A. Saunders, J. Phys.: Condens. Matter 11, 9165 (1999). 
[14] A. G. Shikerkar, J. A. E. Desa, P. S. R. Krishna, and R. Chitra, J. Non-Cryst. Solids 270, 234 (2000).

[15] G. Mountjoy, J. M. Cole, T. Brennan, R. J. Newport, G. A. Saunders, and G. W. Wallidge, J. Non-Cryst. Solids 279, 20 (2001).

[16] H. Y. P. Hong, Acta Cryst. B 30, 468 (1974).

[17] G. I. Dorokhova and O. G. Karpov, Kristallografiya 29, 677 (1984).

[18] U. Hoppe, J. Non-Cryst. Solids 195, 138 (1996).

[19] U. Hoppe, G. Walter, and D. Stachel, Silikattechnik 41, 227 (1990).

[20] U. Hoppe, G. Walter, R. Kranold, D. Stachel, and A. Barz, J. Non-Cryst. Solids 192\&193, 28 (1995).

[21] U. Hoppe, G. Walter, D. Stachel, A. Barz, and A. C. Hannon, Z. Naturforsch. 52a, 259 (1997).

[22] R. K. Brow, C. A. Click, and T. M. Alam, J. NonCryst. Solids 274, 9 (2000).

[23] H. Ebendorff-Heidepriem, W. Seeber, and D. Ehrt, J. Non-Cryst. Solids 163, 74 (1993).
[24] K. Meyer, A. Barz, and D. Stachel, J. Non-Cryst. Solids 191, 71 (1995).

[25] H. F. Poulsen, J. Neuefeind, H.-B. Neumann, J. R. Schneider, and M. D. Zeidler, J. Non-Cryst. Solids 188, 63 (1995).

[26] J. H. Hubbell, Wm. J. Veigele, E. A. Briggs, R. T. Brown, D. T. Cromer, and R. J. Howerton, J. Phys. Chem. Ref. Data 4, 471 (1975).

[27] Y. Waseda, in: The Structure of Non-Crystalline Materials, McGraw-Hill, New York 1980, p. $11 \mathrm{ff}$.

[28] A. C. Hannon, W. S. Howells, and A. K. Soper, IOP Conf. Series vol. 107, 193 (1990).

[29] E. A. Lorch, J. Phys. C 2, 229 (1969).

[30] A. J. Leadbetter and A. C. Wright, J. Non-Cryst. Solids 7, 23 (1972).

[31] D. Marquardt, SIAM J. Appl. Math. 11, 431 (1963).

[32] U. Hoppe, R. Kranold, D. Stachel, A. Barz, and A. C. Hannon, Z. Naturforsch. 55a, 369 (2000). 